\title{
Targeted, Sustainable, Adept: Transforming Jackson State University STEM PD Delivery for Mississippi 6-12th Grade Teachers During COVID-19
}

\author{
Nisaa Kirtman ${ }^{1}$, Teresa Demeritte ${ }^{2}$, Cary Smith², Vida Amouzandeh², and Mehri Fadavi² \\ ${ }^{1}$ Rockman et al Cooperative, Berkeley, CA and ' ${ }^{2}$ Jackson State University, Department of Chemistry, Physics, and Atmospheric Sciences (CPAS), Jackson, MS
}

Keywords: STEM education, professional development, HBCU, underrepresented minorities, virtual teaching, virtual student learning, K12 STEM learning

Publication Date: October 4, 2021

DOI: https://doi.org/10.15695/jstem/v4i4.04

\begin{abstract}
Since 2017, Jackson State University's (JSU) Minority Advancement through Recruitment and Retention in Science via Outreach Program (MARRS-OP) developed a series of professional development (PD) programs designed for 6th-12th science teachers in under-resourced Mississippi school districts. Due to COVID-19, MARRS-OP's original program design was modified to implement innovative online PD courses, designed to expand and sustain the reach of STEM teaching and learning opportunities - particularly for lab experiments. The PD topics included science-subject-based courses centered around equity, science, and technology. Tools for assessing MARRS-OP outcomes included a remote readiness screener for data collection, pre- and post-program survey data collection, and teacher presentation reviews. Despite an array of challenges, teachers reported statistically significant increases in confidence in their ability to teach biology and physics. Teachers also saw value in remote $\mathrm{PD}$, as it provided the ability to experience virtual instruction from their students' perspective, and the opportunity to collaborate with other teachers and expand their network. This article shows that by preparing science teachers to customize approaches for their students, and maintain flexibility, that initiatives such as MARRS-OP can serve as an empowering resource for teachers despite the accessibility and engagement challenges encountered by the sudden shift to online pedagogy.
\end{abstract}

\section{INTRODUCTION}

As pre-school to post-graduate educators began revising courses and curricula to meet the urgent demand for online instruction occasioned by the COVID-19 pandemic, funding from the US Department of Education's Minority Science and Engineering Improvement Program (MSEIP) facilitated an immediate, effective, sustainable transition to virtual STEM instruction and activities for MARRS-OP, a PD program at JSU, Mississippi's only urban university and the nation's 4th largest Historically Black College and University (HBCU). Support from the MSEIP contributed to countering COVID-19's incursions on teaching and learning in Mississippi by furthering the reach of innovative STEM programming. This support was instrumental in helping MARRSOP's research and administrative teams successfully manage an unsought, but critical, test of online teaching and learning strategies, and the potential of these strategies to augment STEM exploration, opportunities, and achievement among Mississippi educators and underserved minority students.
The spring semester of 2020 brought with it an unprecedented national and global emergency in the form of the COVID-19 pandemic. Nationwide social distancing recommendations forced teachers accustomed to in-person classes to pivot suddenly from face-to-face teaching to remote instruction using 'virtual' formats - irrespective of their ability or capacity to do so - and to successfully engage their students in remote learning environments, irrespective of access, writ large. The immediate result was nationwide educator consternation: teachers not only faced unprecedented technical and capacity demands, but shared their students' social, emotional, and learning challenges. MSEIP support had already helped JSU research and administrative teams in the Department of Chemistry, Physics, and Atmospheric Science (CPAS) shift a 'rhetoric of concern' for underserved minority students' STEM aspirations to opportunities for realizing those hopes. These longstanding, stable teams were thus equipped to quickly parlay a strong programmat- 
ic foundation and a wealth of STEM educator and resource networks into meeting the educational challenges summarily unfolding with COVID-19.

In March 2020, public schools in Mississippi already faced a surfeit of challenges in a state grappling with its K-12 education quality, achievement ratings, and disappointing graduation rates. Nearly $24 \%$ of the state's residents (primarily Black residents) live below the poverty line; its K-12 'achievement ranking' fell to 64.1 out of 100 according to the 2019 Education Week report (the 5th lowest in the country); and a number of rural counties apportion even the uncontroversial benefit of a school nurse between widely separated schools to meet budget constraints (Editorial Projects in Education, 2019). Unsurprisingly, the state perennially loses teachers to nearby Alabama, Louisiana, and Tennessee schools offering better pay. Thus, in the midst of a pandemic that plagued educators nationwide, teachers in Mississippi's many under-resourced schools faced particularly fraught challenges in developing effective teaching and learning strategies for the Black, underserved minority, and lower income students in their classrooms. Teachers charged with developing students' foundational skills in STEM classes were not exempt: STEM educators, programs, and departments shared school-wide imperatives to support students, maintain their engagement, and keep them on track academically. They also had to safely translate hands-on science classes and labs to remote settings.

PD programs for teachers nationwide in STEM and beyond quickly grasped that the global COVID-19 pandemic had highlighted the urgency of preparing teachers to educate students remotely. While preserving PD objectives, these programs pivoted to the challenge of effectively securing continuity of instruction across in-person, hybrid, and entirely virtual delivery models to meet the immediate, pandemic-imposed necessity to: (a) more fully mine the requirements and potential of online teaching and learning, and (b) prepare for subsequent events that might again occasion social distancing. National and international teacher PD organizations and other K-12 teacher support forums identified the need to provide quality PD for science teachers and to prepare teachers to educate students in a flexible format, especially with regard to under-resourced and underserved communities (Bichler et al., 2021). Even at this writing, discussions on the optimization of delivery models to maintain student engagement and thereby sustain teaching and learning continue to unfold. Alongside discussions of the synchronous online, remote, asynchronous, hybrid, and blended course configurations under consideration are the added layers of access to the internet and electronic devices, and the undercutting impact a lack of access can exert within under-resourced and impoverished communities (Parolin and Lee, 2021).

\section{BACKGROUND}

The COVID-19 pandemic-imposed a national and global integration of technology to teach remotely and effectively. Remote teaching skills that differ from those appropriate for in-person teaching and learning include: (1) online 'classroom management', (2) lesson planning and creating instruction for online platforms, (3) engaging and motivating students virtually (Jackson and Jones, 2019; Kennedy and Archambault, 2012), and (4) fostering a social and learner presence remotely (Anderson, 2017).

In Spring, 2020, as MARRS-OP teachers joined their peers worldwide in transitioning to online teaching environments, the program's teams and its external evaluators explored the technological and pedagogical knowledge required to develop teacher self-efficacy, defined as "teachers' beliefs about their own capacity as teachers" (Tschannen-Moran et al., 1998). They also examined whether teacher self-efficacy differs fundamentally in online education. The current study presents an opportunity to better understand where teachers 'are' in terms of confidence for teaching online, and how to better support them in an unprecedented transitional phase.

\section{PROGRAM DESCRIPTION}

MARRS-OP, a teacher PD program supported through MSEIP funding, was an active participant in identifying ways to improve effective, remote STEM teaching in the state's 6th through 12th grade STEM classrooms. MARRSOP supported participant teachers in learning remote, as well as face-to-face, strategies responsive to their students' unique needs. The present report documents MARRS-OP's efforts and outcomes. MARRS-OP's vision and mission, to improve STEM teaching and learning throughout the state of Mississippi, were respectively achieved by providing evidence-based PD on STEM teaching and learning to teacher cohorts who face the state's most urgent educational challenges. Specifically, MARRS-OP was designed to improve educators' science content knowledge and teaching efficacy in the secondary level natural science, as well as engineering design. MARRS-OP implemented its objectives by engaging teachers in 16 days of PD on science content and pedagogy (12 days in summer, four school-year Saturdays). While designed for in-person workshops, with online team support, the program shifted to virtual implementation in 2020. Teacher participants assumed and played dual roles - as teacher and as learner - in graduate-level classes that augmented teachers' physical, earth, and space science knowledge through a combination of lectures and hands-on activities which could be implemented in-person and virtually. MARRS-OP programming focused on the Mississippi Curriculum Framework objectives (e.g., "Big Ideas"), but instructors and sessions varied based on participants' needs and interests, and those of their students. Teachers received 
the materials used during the PD to allow them to take back to their students what they had learned. Through this combination of PD courses and instructional materials, short and (eventually) long-term improvements in teachers' content knowledge and teaching efficacy were expected, as were, ultimately, growth in student content knowledge and positive attitudes toward science.

MARRS-OP interventions for teachers consisted of: (1) sixteen days of virtual professional development focused on natural science and engineering design; (2) partnerships and interactions with visiting instructors and national programs; (3) developing and implementing units of instruction in pedagogy; (4) training and support in designing differentiated lessons to address diverse learner needs; (5) training on the recently implemented (2017) Mississippi College and Career Readiness Standards for Science; (6) online professional development; and (7) integration of varied technology projects into summer and academic year workshops.

MARRS-OP participation in the nation's urgent imperative to convert courses, activities, and interventions to virtual, online program offerings began shortly after its initial recruitment for the 2020 Summer workshops (see Figure 1 for program timeline). The shift impacted all program preparations: the workshops had to be held online, and participating teachers equipped to access them. MARRS-OP's lead investigator, with a long tenure in identifying STEM PD faculty for Mississippi teacher workshops, quickly contact-

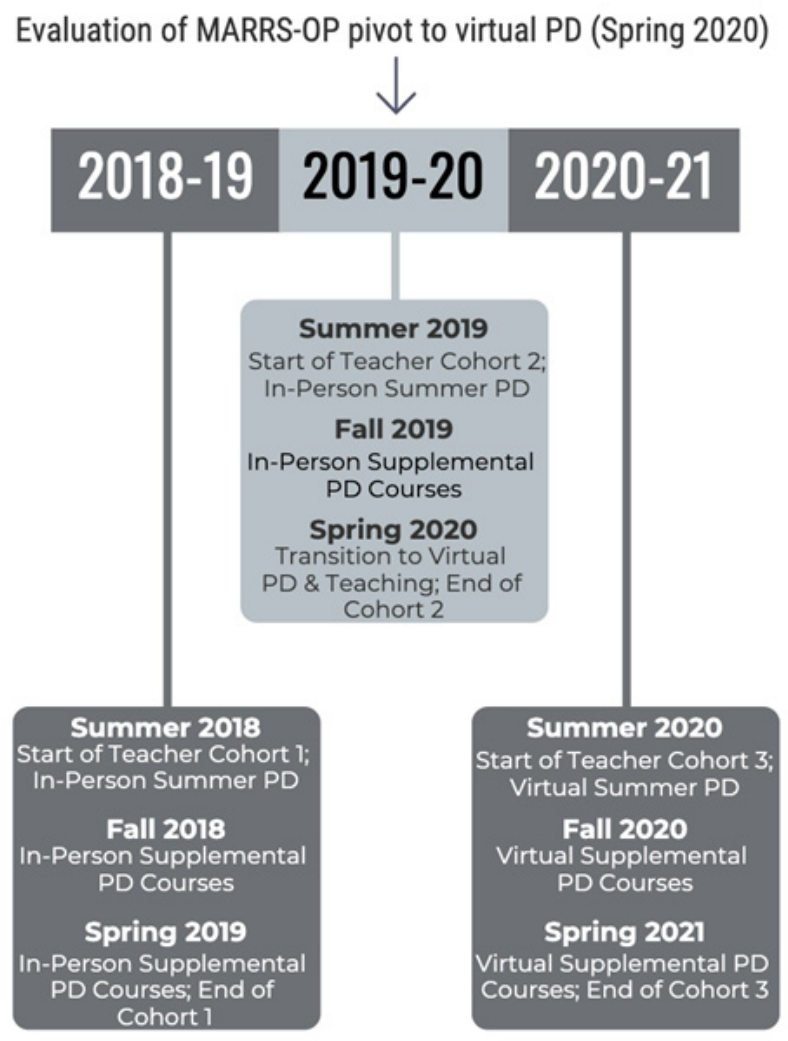

Figure 1. MARRS-OP Timeline: Pivot to Virtual PD and Teaching. ed potential PD workshop leaders able to focus on 'online STEM teaching and learning' for 6th-12th grade educators. The program retained one instructor for all summer workshops, reasoning that the coherence provided by this single instructor, who possessed considerable experience in teaching STEM online content delivery and assessment strategies, would better prepare teachers to migrate their own lesson plans and activities into the virtual environment. The shift to virtual PD programming necessitated the purchase of kits for lab activities, both for the summer workshops and those in the academic year, which were led by a team specializing in Engineering Design, a focus of the state's science standards.

The shift permitted expanding the teacher-participant cohort to almost double the in-person size, and allowed MARRS-OP to furnish participants who needed access to technology ongoing support in obtaining and using it. MARRS-OP goals, as originally outlined, were shifted from a longer-range grasp of new inquiry-based teaching and learning strategies to the development, delivery, and assessment of an effective, grade-appropriate online STEM curriculum, one able to afford opportunities for modified implementation after in-person classrooms were again operative.

Primary MARRS-OP program goals were to: (1) increase teacher content knowledge and knowledge of evidencebased pedagogical and mentoring strategies; (2) improve teacher capacity to incorporate evidence-based strategies within their curricula and classrooms and to effectively enact, guide, and mentor inquiry-based approaches; and (3) increase MS STEM teacher knowledge and confidence in the use of instructional technologies in remote settings.

The following research questions helped guide the current study evaluating the 2020-21 cohort of teacher participants:

Quality of Remote PD Implementation: How do teachers engage and respond to MARRS-OP programming? What elements of the program do they find most and least valuable and why?

Teacher Impacts: To what extent do teachers who participated in MARRS-OP demonstrate growth in (a) teaching practice and (b) self-efficacy for teaching?

Participants. Our teacher sample included 36 teachers from ten school districts in or near Jackson, Mississippi, including Jackson Public School District. Most participants identified as Black or African American (68\%), between the ages of 41-50 (34\%), and as female (84\%). Most teachers majored in biology as undergraduates. Graduate areas of study included biology (19\%), education (19\%), and teaching (13\%).

\section{METHODS}

External evaluators employed both quantitative and qualitative methods to measure the shorter-term impact of the 
MARRS-OP program during the 2020-21 academic year. The goals of this design were to provide formative and summative evaluation information to highlight outcomes and areas of potential improvement, so as to yield evidence of the MARRS-OP program's impact on teachers, and eventually students. Evaluators also employed culturally responsive and equitable evaluation (CREE) approaches by: (1) centering the evaluation in culture and contextual factors (e.g., historical, social, racial, etc.), (2) using a participatory process (Hood et al., 2015), (3) considering the culture of the program evaluated and its participants, and (4) carefully assembling the best evaluation team to carry out and manage the work (Askew et al., 2012).

Participatory evaluation methods included working closely with MARRS-OP staff on instrument design, and allowing staff and stakeholders to maintain some ownership of the evaluation. This approach included empowerment evaluation methods and aimed to use evaluation techniques and findings to help foster program improvements, reflection and continuous quality improvement (CQI) on behalf of those impacted most - MARRS-OP 6-12 teacher participants and, ultimately, their students. It is worth noting that, as program implementation decisions were guided by our original evaluation design, the shift to online PD required adjustments to the program's evaluation design as well. Evaluators pivoted in conjunction with the program by using newly developed instruments; these tools were administered remotely to gather feedback on successes and challenges in the midst of the pandemic, including participants' experience with remote PD and their experience in supporting and engaging students.

Evaluators administered pre and post surveys to teachers and students to measure cognitive and affective changes, including self-efficacy for teaching remotely and formative feedback on the virtual PD received in 2020-2021. Teacher surveys included internally developed questions about professional background, as well as items about teaching attitudes and practices taken from the Science Teacher Efficacy Beliefs Instrument (STEBI), a 5-point Likert scale which measures self-efficacy and outcome expectancy (Riggs and Enochs, 1990). The post survey also asked how teachers were using the materials they received and about their ability to implement what was learned from the virtual PD in their respective, remote classrooms. Evaluators applied quantitative analysis techniques, including descriptive analysis and frequencies. Additionally, pre-post teacher questions were analyzed using paired-samples $t$-test for statistical significance testing and associated effect sizes. Qualitative data was analyzed with a Grounded Theory approach (Strauss and Corbin, 1990), in which a priori coding categories were modified based on the data collected. These codes were then synthesized into broader themes and conclusions.

Journal of STEM Outreach

\section{RESULTS}

Teacher Remote Readiness. Like all educators and students in schools across the U.S., MARRS-OP teachers faced sweeping, unprecedented changes to their teaching as the result of a pandemic that closed school buildings across Mississippi in the spring of 2020. The present section offers teachers' perspectives on some of those changes. Evaluators surveyed participants in late April, 2020 (prior to end-of-year student data collection) to document how ready they felt to deliver instruction remotely, what supports and resources they needed, and what their expected priorities and plans were for the 2020-2021 school year. Evaluators transferred all student science tests and surveys to an online format. Teachers were notified that their students could complete their post-program science test and survey online, either on a smartphone, tablet, laptop or desktop computer.

At the time the survey was administered the effects of the pandemic were already in full force. However, nearly all the teachers who responded to our "Remote Readiness Survey" reported continuing with regularly scheduled courses in the midst of school closures. When asked if teachers were able to manage data collection and instrument administration remotely with their students, most teachers responded "yes" (40\%). Thirty-five percent of teachers responded "maybe" to whether or not they would be able to manage data collection remotely, while $25 \%$ reported "no." Using a 5-point scale $(1=$ Not at all confident; $5=$ Extremely confident $)$, teachers' felt neutral $(M=2.95)$, or neither confident or lacking confidence, about how confident they felt administering student science tests and surveys remotely.

MARRS-OPs' Transition to Virtual PD: Teacher Feedback. What were some of the positive aspects of this virtual PD program? Teachers saw continued value in remote PD as it provided strategies for teaching students remotely. Participants commented on: being able to see virtual instruction from students' perspectives; engagement strategies for remote learning; the possibility of collaborating virtually; the use of technology; and saving time on travel in order to attend the PD workshops in-person (Table 1).

\section{Self-Efficacy for Online Teaching and Remote Student}

Data Collection. Each year, teachers are required to assess their student's content knowledge and self-efficacy for learning science. While four teachers reported not needing support with remote student assessment administration as part of the program evaluation, teachers provided more detail about their additional concerns during the initial period of transitioning to remote teaching in Spring, 2020. The majority of these concerns referred to their students' limited access to computers or electronic devices, as well as their lack of access to the internet (Wi-Fi or broadband). Two MARRSOP participants suggested making the student assessment 
Table 1. Positive aspects of the virtual PD program 2020-21.

\begin{tabular}{ll}
\hline Formative feedback question & Supporting quote \\
\hline & "Virtual PD session has made me a student, \\
and to view the learning from the student's & perspective." \\
& "It gave teachers a learning environment that \\
& showed a great example of how engaging \\
& online learning could be. It allowed for access \\
& for materials beyond the immediate online time \\
& with the instructors." \\
& "Collaboration was a positive aspect of the \\
& virtual PD program." \\
& "(1) Meeting professionals in the field; (2) \\
& Experiencing several teaching tools that could \\
& be immediately implemented in class; (3) I was \\
able to go out of my comfort zone to perform & some of the engaging activities which seemed \\
So effortless once I was in it like building a & rover, something I wouldn't imagine I could do; \\
benefits of the virtual & (4) I learned a lot from the first summer session \\
MARRS-OP PD sessions? & how to use Zoom effectively for my own \\
& remote instruction." \\
& "Saving time and energy on travel and being \\
& more focused." \\
& "Teachers are taught how to use new resources \\
& virtually." \\
& "Easy access."
\end{tabular}

administration process compatible with teaching platforms and/or applications that they were planning to use or were already using, including Google Classroom and Canvas. Additional comments included brief summaries of the response from school districts, such as the cancelling of all student assessments, school districts' implementation of greater restrictions on materials that could be sent to students due to COVID-19, and observations acknowledging their own capacity to administer surveys and assessments remotely, but needing help with overall facilitation. Table 2 lists teachers' comments on the challenges and barriers related to virtual instruction.

Confidence in Ability to Teach Science Remotely. Overall, despite the presence of upward trends over a period of nine months in teacher's confidence in teaching science and efficacy, we note that nine months may be too short a time to see significant change in many of the areas measured. MARRS-OP participants may simply need more time and practice in implementing what they learned from the PD, as would occur over a period of years. In contrast to the Summer 2020 cohort, teacher participants from the preCOVID-19 cohort reported a statistically significant increase in confidence in their ability to teach biology from the beginning of the year $(M=3.52, S D=1.7)$ compared to the end of the year $(M=3.67, S D=1.75), t(56)=2.85, p<.01$, as well as an increase in confidence in their ability to teach physics from pre $(M=2.37, S D=1.83)$ and post $(M=2.83, S D=$ 1.87), $t(58)=2.45, p<.05$ (Figure 2).

It is worth noting that, in aggregate, teachers receiving
Table 2. Self-Efficacy for Online Teaching \& Remote Student Data Collection (Challenges of virtual instruction).

\begin{tabular}{|c|c|}
\hline Identified challenge & Supporting quote \\
\hline \multirow{5}{*}{$\begin{array}{l}\text { Limited Access to } \\
\text { Computers/ Electronic } \\
\text { Devices and/or Wi-Fi }\end{array}$} & $\begin{array}{l}\text { "Most of my students do not have access to } \\
\text { computers and I don't know their home situation. } \\
\text { I cannot with a clear conscience ask my students } \\
\text { to complete the post assessment. The learning } \\
\text { opportunities that were offered to my students only } \\
3 \text { students opened and none of them completed." }\end{array}$ \\
\hline & $\begin{array}{l}\text { "Most of the students in the (our) County District } \\
\text { live in the rural areas without wi-fi or internet } \\
\text { and it is very difficult to get any work completed } \\
\text { using the computers. I am communicating with } \\
\text { my students and parents during this time getting } \\
\text { assignments done, they are focusing on graduation, } \\
\text { as well as passing core subjects. I'm unable to get } \\
\text { any assignments other than some of the required." }\end{array}$ \\
\hline & $\begin{array}{l}\text { "Not all of my students have access to devices \& } \\
\text { reliable internet...not sure you can help with this." }\end{array}$ \\
\hline & $\begin{array}{l}\text { "Students in my school district are not equipped } \\
\text { with electronic devices or internet access. Several } \\
\text { students did not complete term four class work } \\
\text { because of this issue." }\end{array}$ \\
\hline & $\begin{array}{l}\text { "It is not guaranteed that all students have access } \\
\text { to electronic devices. Seniors (a large section of } \\
\text { my class) are pretty much officially done with } \\
\text { school (their last assignment was due May 1st)." }\end{array}$ \\
\hline \multirow{2}{*}{$\begin{array}{l}\text { The Need for } \\
\text { Compatibility with } \\
\text { Online Teaching } \\
\text { Applications }\end{array}$} & $\begin{array}{l}\text { "Have the test compatible with Google Class- } \\
\text { room." }\end{array}$ \\
\hline & $\begin{array}{l}\text { "I can administer through Canvas; however, } \\
\text { participation will be extremely low. I have a few } \\
\text { students that cannot take tests remotely." }\end{array}$ \\
\hline \multirow{3}{*}{$\begin{array}{l}\text { Additional Comments: } \\
\text { District Responses \& } \\
\text { Help with Administration } \\
\text { Facilitation }\end{array}$} & $\begin{array}{l}\text { "This year, thanks to what we now call COVID-19, } \\
\text { it also started all our school districts quick migra- } \\
\text { tion to the world of online learning. It also marked } \\
\text { the first time in a few decades of operation that } \\
\text { MS-CPAS assessments would be suspended in our } \\
\text { state due to this global pandemic. In our district, all } \\
\text { assessments have been cancelled." }\end{array}$ \\
\hline & $\begin{array}{l}\text { "Our district has tightened regulations over what } \\
\text { we can send out to students due to COVID." }\end{array}$ \\
\hline & $\begin{array}{l}\text { "We have the capability and so long as you can } \\
\text { facilitate us with the distribution, we will be able to } \\
\text { take the assessment." }\end{array}$ \\
\hline
\end{tabular}

the virtual PD did not feel more confident in their ability to teach science, with a notable decrease in the subjects of biology and earth science for teacher participants in the 2020-21 academic year cohort.

\section{Confidence Teaching Science Curriculum Remotely.} Teachers felt slightly more confident overall in teaching science curricula online after nine months. Improvements were minimal and not statistically significant. Due to the pandemic, teachers were asked to assess their ability to teach their students remotely - this particular post (or end-of-year) item was the fourth highest average mean at the end of the year $(M=3.96)$. Three of the items that were negatively worded showed slight increases, but were also not-significant (e.g., "Even if I try hard, I do not teach science as well as other subjects"). 


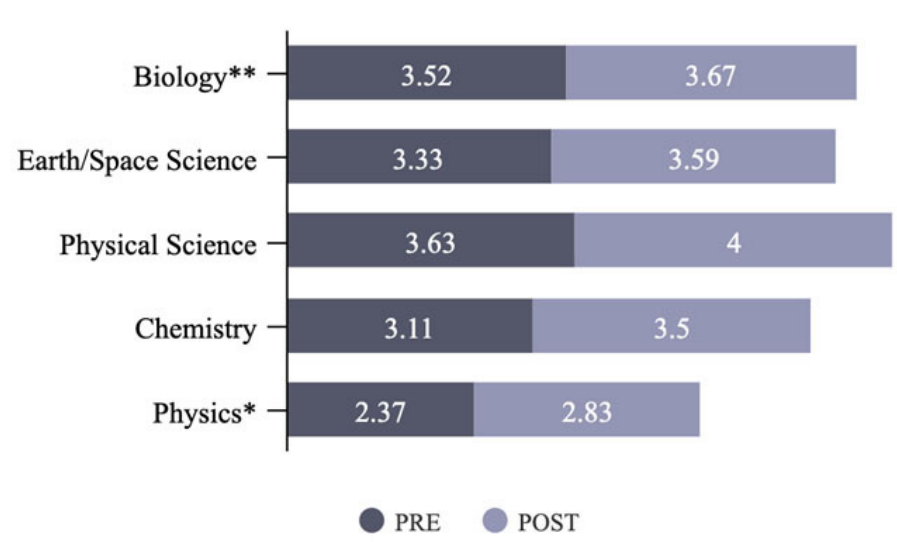

Figure 2. Confidence in Ability to Teach Science: Average Means ( $\mathrm{N}=36) .1=$ Not at all confident, $2=\mathrm{A}$ little confident, $3=\mathrm{In}$ the middle, $4=$ Somewhat confident, $5=$ Extremely confident. ${ }^{*} p<$ $0.5 ;{ }^{* *} p<0.01$.

Changes in Teaching Practice. Using a 5-point scale with 5 being "to a great extent," participants reported changes in the way they used technology in instruction $(M=4.13)$, followed by the instructional methods they employed $(M=$ 3.96).

Expansion of Virtual Teaching Community and Online Tools. MARRS-OP participants were asked a series of questions related to the expansion of their online community of practice nine months after the start of the program. When comparing teachers' activities from the beginning of the school year to nine months later, one activity in particular had increased a great deal, but not to statistical significance: accessing an online community to get support and share ideas about teaching. Teachers also increased their use of formal networks or organizations to get support and share ideas about teaching.

Overall Value of MARRS-OP. Figure 3 illustrates the overall value of MARRS-OP. Most teachers from the current 202021 cohort $(60 \%)$ referred to MARRS-OP as being among the best PD experiences they had had. About 30\% reported
MARRS-OP as a "better than average PD experience," even in a remote setting (33\%). In response to statements about MARRS-OPs' alignment with individual and departmental goals (Figure 4), using a 5-point Likert scale with 1 being "strongly disagree" and 5 being "strongly agree," the majority of responses fell between 3 ("neither disagree or agree") and 4 ("agree"). In response to the program's alignment with teaching goals, with the exception of one statement, all of Cohort 3 teachers rated each statement above average, and slightly, yet, non-significantly higher than the previous year (Cohort 2; Figure 4).

\section{Community Engagement and Relationships During} COVID-19. In the midst of the pandemic, community engagement and trust between the MARRS-OP program and teacher participants has been critical to sustainability. The MARRS-OP administrative team has over a decade of experience in successfully managing the relationships of trust and other program components vital to quality professional development programs and to effective school, community, and school community-oriented collaborations. We have particularly achieved a considerable degree of trust among STEM teachers and school administrators in the largely minority schools and school communities whose teachers are the focus of the MSEIP Title III/V award. In addition, we have developed strong relationships with national educators who have contributed to our programs - relationships pivotal to successfully navigating the sudden shift to online programming with COVID-19. The fiscal stability to which this award contributes allows this team to continue to assure effective outreach, recruitment, enrollment, retention, and data collection across project lifetime.

All networking opportunities with similarly targeted programs are beneficial. A corollary impact of our workshops arises through relationships formed between the teacher-participants themselves and with departmental and other JSU teachers, staff members, and administrators. In the Summer 2020 online context, however, these relationships

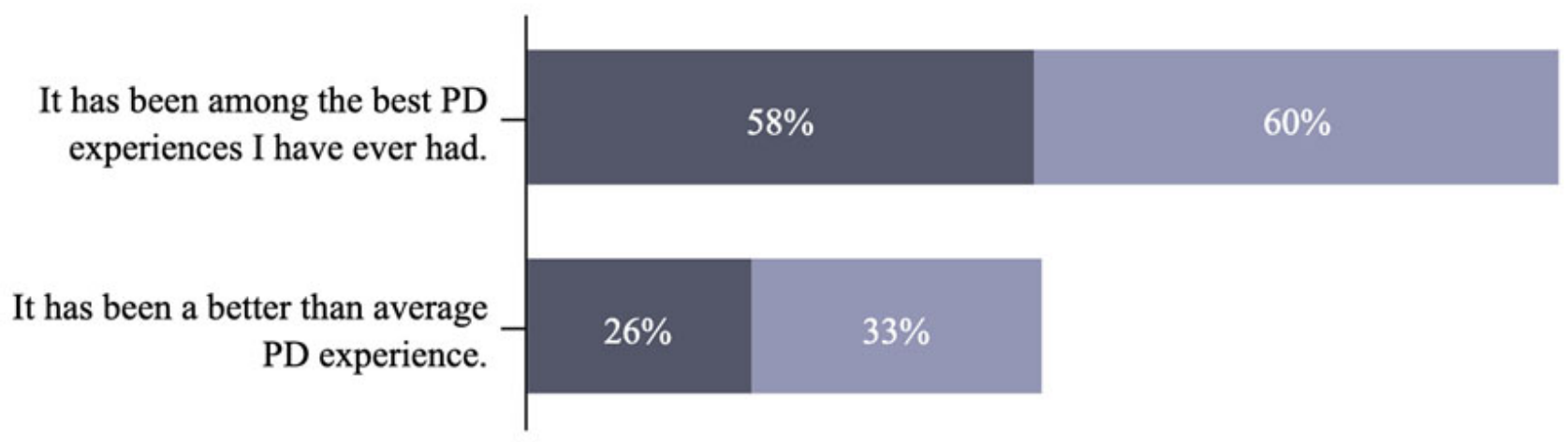

PRE

Figure 3. Value of MARRS-OP in Percentages: Average Means (N=36). 1=Not at all confident, $2=A$ little confident, $3=$ In the middle, 4=Somewhat confident, 5=Extremely confident. 
MARRS has been consistent with my own goals for professional development.

MARRS has been consistent with my school or department's plan to improve practice and student learning.

MARRS has provided me with resources, tool and activities that have helped me implement my new knowledge and skills in my classroom.

MARRS supports state or district standards (e.g., MS, College and Career Readiness Standards in Science).

MARRS supports state or district assessment.

MARRS is similar to other professional development activities I have experienced/attended in the past.

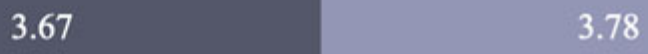

3.56

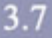

3.56

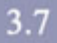

3.65

Figure 4. MARRS-OP's Alignment with Teaching and Goals: Average Means (N=36). 1=Not at all confident, $2=A$ little confident, $3=$ In the middle, $4=$ Somewhat confident, $5=$ Extremely confident.

were further extended to a greater number of teacher (peer) participants, and to STEM instructors who led the workshops - a nationally recognized STEM educator/researcher experienced in online STEM content delivery and effective strategies for engaging low-income and minority students in STEM concepts and activities. The MARRS-OP administrative team provided further support for implementing workshop-introduced activities. These avenues of collaboration, access, and guidance were expected to yield positive reports to students, parents, and guidance counselors about JSU STEM resources and access to beneficial partnerships and opportunities. Improved infrastructure in science cannot be underestimated. Examples of MARRS-OP support for research infrastructure are the improved labs and increased supplies provided for the JSU junior faculty and fledgling researchers recruited to undergraduate STEM programs from MARRS-OP teacher-participants' schools. These faculty and the research experiences they offer comprise an important recruitment component.
Considerations for the New 2021-22 Teacher Cohort and Academic Year. At the time of this writing, formal feedback on teaching and learning experiences from the Spring of 2021 (end of academic year) were not yet available. However, certain anecdotal observations can be made. Fall 2020 is different from Spring 2020 in that there was no rapid change or panic during the former, even though some of the pandemic conditions were the same. Teachers appeared to be more prepared to teach in fall than they were in spring due to more strict guidelines and clearly communicated district-wide plans for the year of 2020-2021.

Upon reflection, certain important questions emerged that might help in envisioning the direction of future MARRSOP teacher PD.

- How can technology be leveraged to front load flexibility in 6th-12th science course design and delivery?

- Which teaching practices adopted during the pandemic should we continue to use, going forward, in order to maintain the momentum of growth? 
- Does the expectation of customization and flexibility carry over to the infrastructure (ex. classroom technology, online course/lab availability) that supports it?

- What if MS districts, schools, and/or classrooms are poorly equipped?

- In what ways can teachers be supported to teach students how to learn or be independent learners in science and/ or STEM?

- How can schools which do not have dedicated Informational Technology (IT) or educational technology support units, work to support teachers and students from under-resourced communities?

- What is JSU's role in this ever-emerging scenario of constant change?

- How has the pandemic changed the way STEM teacher modify operating procedures so as to ensure flexibility for short-term disruptions that usually occur annually?

- Going forward, how will the pandemic affect typical 6th-12th policies on things like late submissions, assessments, and absenteeism?

\section{DISCUSSION}

The purpose of the current report is to provide an update on MARRS-OP professional development evaluation activities completed from the summer of 2020 to the spring of 2021 (an ongoing data collection cycle). The MARRS-OP PD program provided focused and targeted opportunities for 6-12 science teachers that were shown to be critical for both new and veteran Mississippi teachers at the start of academic years and during a nationwide pivot to virtual teaching due to the pandemic.

MARRS-OP's offerings since 2018 included essential training on how best to teach 6-12 science curricula, the use of hands-on exercises and inquiry, culturally responsive practices, and more. The goals of MARRS-OP were to: (a) increase teacher content knowledge and knowledge of evidence-based pedagogical and mentoring strategies, (b) improve teacher capacity to incorporate evidence-based strategies within their curricula and classrooms and to effectively enact, guide, and mentor inquiry-based approaches, and (c) increase MS STEM teacher knowledge and confidence in the use of instructional technologies.

Some of the key findings from this year's MARRS-OP cohort are as follows:

- Forty percent of teachers reported being ready for remote student assessment administration. The primary concern expressed by teachers on pivoting to remote student assessments included limited access to computers, electronic devices and/or Wi-Fi.
- Teachers reported changes in their instructional methods as a result of participating in the MARRS-OP PD, and adapting their teaching and curriculum to meeting MS state standards and requirements, from pre to post. Teachers also reported changing the way they use technology in instruction at the end of the year $(M=4.13$ out of $5 ; 5=$ To a great extent .

- While MARRS-OP teachers from the 2020-2021 academic year reported a statistically significant increase in confidence in their ability to teach biology from the beginning of the year compared to the end of the year, alongside an increase in confidence in their ability to teach physics from pre to post, the 2020-21 teachers' confidence in science knowledge remained unchanged, with minimal but non-significant increases in biology, earth/space science, physical science, physics, and chemistry.

MARRS-OP participants' students were taught in either a fully online or a blended format for the remainder of 2020, after which all courses were delivered asynchronously. MARRS-OP teacher participants continued their PD 100\% online for the remainder of the 2021 academic year.

The longstanding importance of the MARRS-OP program lies in its preparation of Mississippi teachers to rapidly transition to flexible and accommodating teaching modalities that enable learning continuity for underrepresented communities. It must be emphasized that flexibility is the key to such pivots, whatever the teaching modality may be and whatever the teaching community. The goal of MARRSOP was twofold: to implement PD objectives as previously planned, and to prepare teachers to be flexible in case the pandemic required them to pivot from any given teaching modality.

Irrespective of modality, the COVID-19 pandemic spotlighted that teachers always need to be prepared to respond to change. Students, post-pandemic, may demand more blended and hybrid courses as compared to face-to-face courses, and may thrive with such adjustments. By preparing STEM teachers to teach with great intention, focus, and flexibility and to customize approaches for students in their classes, initiatives such as MARRS-OP can serve as empowering resources. While COVID-19 has shown to be an unpredictable and, albeit, a potentially rewarding challenge, MARRS-OP and its peer programs nationwide equally show that - by equipping teachers to face the future head-on, encouraging teacher-led innovations, and providing these crucial educators with the resources needed to engage innovative strategies that will emerge - we can support our teachers in effectively implementing new modalities and further their great potential to advance the STEM achievements of underrepresented students in underserved communities, diverse learners, and our nation. 


\section{AUTHOR INFORMATION \\ Corresponding Author}

Nisaa Kirtman, M.A., Ph.D. Candidate, Rockman et al., 2203 McGee Avenue, Berkeley, CA, 94703. (415) 544-0788. nisaa@rockman.com

\section{Author Contributions}

The manuscript was written through contributions of all authors. All authors have given approval to the final version of the manuscript.

This work is licensed under a Creative Commons Attribution 4.0 International (CC BY 4.0) License.

\section{ACKNOWLEDGMENTS}

We would like to acknowledge our appreciation of Dr. Nancy Ruzycki, whose outstanding provision of the Summer 2020 online MARRS-OP teacher workshops made our abrupt PD program shifts in response to COVID-19 not merely a necessary response but an achievement. We would also like to thank our colleague Jo Anne Fordham for her thought leadership and work on JSU K12 teacher and faculty development programming, including MARRS-OP and the TIGER-STEM faculty development program (Taking the Initiative to Grow Enrollment and Retention of Minority Students in STEM).

\section{FUNDING SOURCES}

Funding was received from the U.S. Department of Education through its Minority Science and Engineering Improvement Program (MSEIP).

\section{ABBREVIATIONS}

CPAS: Chemistry, Physics, and Atmospheric Sciences; CQI: Continuous Quality Improvement; CREE: Culturally Responsive and Equitable Evaluation; HBCU: Historically Black College and University; JSU: Jackson State University; MARRS-OP: Minority Advancement through Recruitment and Retention in Science via Outreach Program; MSEIP: Minority Science and Engineering Improvement Program; PD: Professional Development; STEBI: Science Teacher Efficacy Beliefs Instrument; TIGER-STEM: Taking the Initiative to Grow Enrollment and Retention of Minority Students in STEM

\section{REFERENCES}

Anderson, T. (2017). How communities of inquiry drive teaching and learning in the digital age. Contact North. https://tinyurl.com/y68789b9

Askew, K., Beverly, M.G., and Jay, M.L. (2012). Aligning collaborative and culturally responsive evaluation approaches. Evaluation Program Planning, 35(4), 552-7. doi: 10.1016/j.evalprogplan.2011.12.011. Epub 2011 Dec 31. PMID: 22284941.

Bichler, S., Gerard, L., Bradford, A., and Linn, M. C. (2021). Designing a remote professional development course to support teacher customization in science. Computers in Human Behavior, 123, 1-14. https://doi-org.proxy1.ncu. edu/10.1016/j.chb.2021.106814

Cho, M-H., and Shen, D. (2013). Self-regulation in online learning. Distance Education, 34(3), 290-301. https://doi.org/1 $0.1080 / 01587919.2013 .835770$

Editorial Projects in Education (EPE). (2019). Quality Counts 2019: Finance. Grading the States. Education Week, 38(34).

Hood, S., Hopson, R., and Kirkhart, K. E. (2015). Culturally responsive evaluation. In K. E. Newcomer, H. P. Hatry, and J. S. Wholey (Eds.), Handbook of Practical Program Evaluation (4 ed., pp. 281-317). Jossey-Bass Inc. https://doi. org/10.1002/9781119171386.ch12

Jackson, B. L., and Jones, M. (2019). Where the rubber meets the road: Exploring the perceptions of in-service teachers in a virtual field experience. Journal of Research on Technology in Education, 51(1), 7-26. https://doi.org/10.1080/1539 1523.2018.1530622

Kennedy, K., and Archambault, L. (2012). Design and development of field experiences in online learning environments. Journal of Applied Instructional Design, 2(1), 35-49. https://doi.org/10.1177/0022487111433651

Parolin, Z., and Lee, E. K. (2021). Large socio-economic, geographic and demographic disparities exist in exposure to school closures. Nature Human Behavior, 5(4), 522-528. https://doi-org.proxy1.ncu.edu/10.1038/s41562-02101087-8

Riggs, I. M., and Enochs, L. G. (1990). Toward the development of an elementary teacher's science teaching efficacy belief instrument. Science Education, 74(6), 625-637. https://doi. org/10.1002/sce.3730740605

Tschannen-Moran, M., and Hoy, A. W. (2001). Teacher efficacy: Capturing an elusive construct. Teaching and Teacher Education, 17(7), 783-805. https://doi.org/10.1016/S0742051X(01)00036-1 